\title{
Cell line and patient-derived xenograft models reveal elevated CDCP1 as a target in high-grade serous ovarian cancer
}

Brittney S Harrington ${ }^{1,2}$, Yaowu He $e^{1,2}$, Claire M Davies ${ }^{1,2,3}$, Sarah J Wallace ${ }^{2,3}$, Mark N Adams ${ }^{1}$, Elizabeth A Beaven ${ }^{2,3}$, Deborah K Roche ${ }^{1,2}$, Catherine Kennedy ${ }^{4}$, Naven P Chetty ${ }^{2,3}$, Alexander J Crandon ${ }^{2,3}$, Christopher Flatley ${ }^{1}$, Niara B Oliveira ${ }^{2,3}$, Catherine M Shannon ${ }^{2,3}$, Anna deFazio ${ }^{4}$, Anna V Tinker ${ }^{5}$, C Blake Gilks ${ }^{6}$, Brian Gabrielli ${ }^{7}$, Donal J Brennan ${ }^{2,3}$, Jermaine I Coward ${ }^{1,2,3}$, Jane E Armes ${ }^{2,3}$, Lewis C Perrin ${ }^{2,3}$ and John D Hooper ${ }^{\star}, 1,2$

${ }^{1}$ Mater Research Institute, University of Queensland, Translational Research Institute, Woolloongabba, QLD 4102, Australia; ${ }^{2}$ Mater Ovarian Cancer Research Collaborative, Mater Adult Hospital, South Brisbane, QLD 4101, Australia; ${ }^{3}$ Mater Health Services, South Brisbane, QLD 4101, Australia; ${ }^{4}$ Department of Gynaecological Oncology, Westmead Hospital and Centre for Cancer Research, Westmead Millennium Institute, Westmead, NSW 2145, Australia; ${ }^{5}$ Cheryl Brown Ovarian Cancer Outcomes Unit, Division of Medical Oncology and Vancouver Centre, British Columbia Cancer Agency, Vancouver, BC, Canada; ${ }^{6}$ Department of Pathology and Laboratory Medicine, Vancouver General Hospital, University of British Columbia, Vancouver, BC, Canada and ${ }^{7}$ The University of Queensland Diamantina Institute, Translational Research Institute, Woolloongabba, QLD 4102, Australia

Background: Development of targeted therapies for high-grade serous ovarian cancer (HGSC) remains challenging, as contributing molecular pathways are poorly defined or expressed heterogeneously. CUB-domain containing protein 1 (CDCP1) is a cell-surface protein elevated in lung, colorectal, pancreas, renal and clear cell ovarian cancer.

Methods: CUB-domain containing protein 1 was examined by immunohistochemistry in HGSC and fallopian tube. The impact of targeting CDCP1 on cell growth and migration in vitro, and intraperitoneal xenograft growth in mice was examined. Three patientderived xenograft (PDX) mouse models were developed and characterised for CDCP1 expression. The effect of a monoclonal anti-CDCP1 antibody on PDX growth was examined. Src activation was assessed by western blot analysis.

Results: Elevated CDCP1 was observed in 77\% of HGSC cases. Silencing of CDCP1 reduced migration and non-adherent cell growth in vitro and tumour burden in vivo. Expression of CDCP1 in patient samples was maintained in PDX models. Antibody blockade of CDCP1 significantly reduced growth of an HGSC PDX. The CDCP1-mediated activation of Src was observed in cultured cells and mouse xenografts.

Conclusions: CUB-domain containing protein 1 is over-expressed by the majority of HGSCs. In vitro and mouse model data indicate that CDCP1 has a role in HGSC and that it can be targeted to inhibit progression of this cancer.

In 2012, there were 239000 new cases of epithelial ovarian cancer (EOC) worldwide and it is the eighth leading cause of death from cancer in women (Ferlay et al, 2015). The five-year survival rate at around $40-44 \%$ has improved only modestly for ovarian cancer over the last three decades (Siegel et al, 2013). Continued poor survival derives from the late stage of disease diagnosis and

*Correspondence: Dr JD Hooper; E-mail: john.hooper@mater.uq.edu.au

Revised 10 November 2015; accepted 8 December 2015; published online 4 February 2016

(c) 2016 Cancer Research UK. All rights reserved 0007 - 0920/16 
intrinsic and acquired resistance to current cytotoxic and targeted therapies (Vaughan et al, 2011; Coleman et al, 2013). Of the four major histological EOC subtypes, the most common is high-grade serous carcinoma (HGSC), representing approximately $70 \%$ of cases (McCluggage, 2011). Historically, HGSC has been thought to originate from the surface epithelium of the ovary; however, recent human data and findings from mouse models suggest that the fallopian tube is a common, and potentially predominant, site from which HGSC originates (Kim et al, 2012; Perets et al, 2013; Sherman-Baust et al, 2014; Gilks et al, 2015).

CUB domain containing protein 1 (CDCP1) is a membrane spanning cellular receptor that is produced as a heavily glycosylated $135-\mathrm{kDa}$ form that can be proteolytically cleaved to $70 \mathrm{kDa}$ in cell lines and tissues (Hooper et al, 2003; Wortmann et al, 2009; Adams et al, 2015). Elevated expression of CDCP1 correlates with poor outcome in renal (Awakura et al, 2008; Emerling et al, 2013), lung (Ikeda et al, 2009), colorectal (Gao et al, 2013), pancreatic (Miyazawa et al, 2010) and clear cell ovarian ( $\mathrm{He}$ et al, 2015) cancer. Data from pre-clinical models suggest that it may have use as a therapeutic target for cancer treatment (Fukuchi et al, 2010; Razorenova et al, 2011; Casar et al, 2012; Emerling et al, 2013; He et al, 2015). For example, a cytotoxin-conjugated chimaeric mouse anti-CDCP1 antibody was effective at reducing subcutaneous tumour growth and lymph-node dissemination of prostate cancer PC3 cells (Siva et al, 2008). In addition, mouse monoclonal (Deryugina et al, 2009) and human antibody single chain variable fragment (Fukuchi et al, 2010) anti-CDCP1 antibodies caused marked a reduction in dissemination of a highly metastatic variant of PC-3 cells in chicken embryo models of metastasis. Mouse monoclonal anti-CDCP1 antibodies also markedly reduced metastasis of these cells implanted orthotopically in mice (Casar et al, 2014). Another mouse monoclonal anti-CDCP1 antibody reduced tumour growth and improved survival of mice carrying subcutaneous breast cancer cell line xenografts (Kollmorgen et al, 2013). Furthermore, we have previously demonstrated that antibody-mediated blockade of CDCP1 significantly increased sensitivity of an ovarian clear cell carcinoma cell line xenograft in mice to carboplatin (He et al, 2015).

The potential importance of CDCP1 in EOC is suggested by data demonstrating significant elevation in both mRNA (Emerling et al, 2013) and protein ( $\mathrm{He}$ et al, 2015) expression in ovarian carcinomas compared with normal ovary and benign ovarian tumours (Adams et al, 2015). This is supported by recent in vitro data, which indicated that inhibition of CDCP1 may have potential for controlling HGSC that is regulated by epidermal growth factor (EGF)/EGF receptor (EGFR) signalling, a pathway that is activated in a high proportion of EOCs (Dong et al, 2012; Adams et al, 2015). In this study, EGF/EGFR signalling caused CDCP1 relocalisation from cell-cell junctions to filopodia in the HGSC cell lines Caov3 and OVCA420 (Dong et al, 2012). Epidermal growth factor also inhibited palmitoylation and degradation of CDCP1, promoting recycling of the internalised protein to the cell surface (Adams et al, 2015). Disruption of CDCP1 in these cell lines, via short-hairpin RNA (shRNA)-mediated silencing and a function blocking antibody, was effective at reducing EGF-induced cell motility, demonstrating the importance of increased levels of CDCP1 on the cell surface to a process that is important in progression of EOC (Dong et al, 2012).

The aim of this study was to further assess the functional importance of CDCP1 as a putative therapeutic target in HGSC. We examined CDCP1 expression in 292 HGSC tumours, 7 HGSCs within the fallopian tubes from women with HGSC of the ovary, 4 non-diseased fallopian tubes from women with HGSC and normal fallopian tubes from 8 non-cancer patients, demonstrating that $77 \%$ of malignant HGSC cases express this protein. Using shRNAmediated silencing, we confirmed that CDCP1 has an important role in migration of HGSC cells in vitro, and also demonstrated that it promotes tumour growth in a mouse model. Finally, we showed for the first time the effectiveness of antibody-mediated functional inhibition of CDCP1 at reducing growth of a patientderived xenograft (PDX) mouse model. These data suggest that CDCP1 has an important and targetable role in HGSC.

\section{MATERIALS AND METHODS}

Patient samples and immunohistochemistry. Research involving human subjects was approved by the Mater Health Services Human Research Ethics Committee. Informed consent was obtained from all patients. A tissue microarray (TMA) containing duplicate cores from 212 HGSC cases was obtained from the Cheryl Brown Ovarian Cancer Outcomes Unit, University of British Columbia, Vancouver, Canada (Derycke et al, 2010). For these cases, tumour stage was available as well as data allowing calculation of disease-free and overall survival. Also, for 104 cases the site of recurrence was available (local, lymphatic local/distant, pelvic/abdominal and extra-abdominal). None of the patients received neoadjuvant chemotherapy, and all except seven received adjuvant platinum-based chemotherapy. A second TMA containing duplicate cores was generated from archival samples of 96 HGSC cases from the Mater Hospital, South Brisbane, Australia, using previously described approaches (Kumar et al, 2004; Armes et al, 2013). For this TMA tumour stage was available as well as deidentified patient information, from the Queensland Centre for Gynaecological Cancer database (Obermair et al, 2001), that allowed calculation of disease-free and overall survival. In total, these two TMAs contained 308 cases of which 292 were evaluable for CDCP1 expression with cores of the remaining 16 cases lost during processing. Data from these 292 cases were used for Kaplan-Meier survival analysis and examination for correlations with stage, and, for 104 cases, site of recurrence. Independent TMAs containing cores from 180 HGSC cases, with known TP53 gene mutation status for 30 cases, were obtained from the Gynaecological Oncology Biobank at Westmead, Sydney, Australia (Ahmed et al, 2010; Emmanuel et al, 2014). Another TMA, generated from archival specimens from the Mater Hospital, contained normal fallopian tube $(n=8)$ and non-diseased fallopian tube from women with HGSC $(n=4)$. In addition, from the Mater Hospital archive we obtained full face sections of HGSC within fallopian tube from women with synchronous ovarian HGSC $(n=7)$, with evidence supporting that these are primary fallopian tube carcinomas (Singh et al, 2015). Immunohistochemistry was performed using the Ventana Benchmark Ultra Automated Staining System (Ventana Medical Systems, Tucson, AZ, USA) using rabbit anti-CDCP1 carboxyl terminal antibody \#4115 (1:50; Cell Signaling Technology, Genesearch, Arundel, QLD, Australia) as previously described (He et al, 2015). The 96 case TMA was also stained for p53 using antibody DO-7 (Sigma-Aldrich, Castle Hill, NSW, Australia) as previously described (Kobel et al, 2010). Scoring of staining into negative, weak, medium and strong, and acquisition of images were performed as previously described (Armes et al, 2013; He et al, 2015). On the basis of p53 staining, the TP53 mutation status was inferred for cases on the 96 case TMA as null, missense or wild type, using a previously described protocol (Yemelyanova et al, 2011). Thus, in combination with the Westmead TMAs, TP53 mutation status was available for 126 cases. For statistical analysis of immunohistochemical staining, CDCP1 expression was separated into negative (none) and positive (weak, medium and strong). Disease-free and overall survival analyses $(n=292)$ were performed using the Kaplan-Meier function, and CDCP1-negative and -positive groups compared using the log-rank test (Mantel-Cox). For correlative analyses of 
immunohistochemical data vs stage $(n=292)$, site of recurrence $(n=104)$, TP53 mutation status $(n=126)$ and CDCP1-negative and -positive groups were compared using Chi-Square analysis unless contingency table cell values were less than five, when Fisher's exact test was used with the Stata statistical software (StataCorp LP, Survey Design and Analysis Services Pty Ltd, Lyneham, ACT, Australia).

Cell lines and silencing of CDCP1 expression. The HGSC cell line OV90 (ATCC, Manassas, VA, USA) was grown in a $1: 1$ ratio of MCDB 105 and M199 media (Sigma-Aldrich) with 15\% (v/v) fetal calf serum (FCS; Gibco, Life Technologies, Mulgrave, VIC, Australia). The ovarian cancer cell lines SKOV3 and HEY (ATCC) were grown in RPMI media containing 10\% (v/v) FCS. All cell lines were cultured in the presence of penicillin (100 units per $\mathrm{ml}$ ) and streptomycin (100 units per $\mathrm{ml}$ ) at $37^{\circ} \mathrm{C}$ in a humidified $5 \% \mathrm{CO}_{2}$ atmosphere. SKOV3 cells stably expressing luciferase were generated as previously described (He et al, 2015). Expression of CDCP1 was stably suppressed in OV90, HEY and SKOV3 cells as previously described (Wortmann et al, 2011) using two pLKO.1 lentiviral shRNA knockdown constructs (target sequence for $\mathrm{V} 1$ : GCTCATAAGAGCATCGGTTTA and target sequence for V2: GCATTGCAAACCGCTCATCTA; OpenBiosystems, Millennium Science, Surrey Hills, NSW, Australia) with a scramble shRNA construct (Addgene) as a control.

Western blot analysis. Whole-cell lysates were collected using RIPA buffer (Sigma-Aldrich) with $1 \times$ Complete protease inhibitor cocktail (Roche, Castle Hill, NSW, Australia), $2 \mathrm{mM}$ sodium vanadate, and $10 \mathrm{mM}$ sodium fluoride, and used in western blot analysis as described previously (He et al, 2015) using mouse monoclonal anti-p53 antibody DO-7 (Sigma-Aldrich), rabbit antiCDCP1 carboxyl terminal antibody \#4115, rabbit anti-phosphoSrc-Tyr416 (p-Src-Y416) antibody \#2101, mouse anti-Src antibody \#2110 (Cell Signaling Technology) or a mouse monoclonal antiglyceraldehyde-3-phosphate dehydrogenase (GAPDH) antibody (Merck Millipore, Kilsyth, VIC, Australia). All antibodies were used at a dilution of $1 / 2000$, except the anti-GAPDH antibody that was used at a dilution of $1 / 10000$.

In vitro assays. Assays assessing proliferation of adherent cells were performed as previously described (He et al, 2015). For cell migration assays, cells $\left(5 \times 10^{4}\right.$ per chamber $)$ were seeded onto a polycarbonate nucleopore membrane in the top of a Transwell chamber (Corning, Sigma-Aldrich) in serum-free medium and allowed to migrate across the membrane to the bottom of the well over $48 \mathrm{~h}$ towards $10 \%$ FCS. The number of cells that migrated and attached to the bottom plate was quantified as described previously (He et al, 2015). For assays examining growth of cells in suspension, cells $\left(8 \times 10^{3}\right.$ per well) were plated into wells of 96 well ultra-low attachment plates (Corning, Sigma-Aldrich) in serum-free medium and cultured for $72 \mathrm{~h}$. In assays assessing the impact of functional blockade of CDCP1, antibody 10D7 or control immunoglobulin (IgG; $50 \mu \mathrm{g} \mathrm{ml}^{-1}$ ) was included in the plating media. Cell viability was measured using a Cell Titer Aqueous One kit (Promega, Alexandria, NSW, Australia) according to the instructions of the manufacturer. For western blot analysis comparing p-Src-Y416, Src and CDCP1 levels in adherent and non-adherent SKOV3 cells, lysates were prepared from cells grown in $10 \mathrm{~cm}$ dishes.

Cell line xenografts in mice. Experiments using mice were approved by the University of Queensland Animal Ethics Committee, and conducted in accordance with the Australian code for the care and use of animals for scientific purposes 8th edition 2013. Luciferase-labelled SKOV3 cells $\left(5 \times 10^{6}\right)$ stably transduced with shCDCP1 or Scramble lentiviral vectors were injected intraperitoneally into 6- to 8-week-old female NOD.Cg$\mathrm{Prkdc}^{\text {scid }} \mathrm{Il2} \mathrm{rg}^{\mathrm{tm} 1 \mathrm{Wjl}} / \mathrm{SzJ}$ (NSG) mice (5 per group; The Jackson
Laboratory, Bar Harbor, ME, USA). Tumour development was assessed weekly by monitoring luciferase signal using an IVIS bioluminescent imaging system (Perkin-Elmer, Glen Waverley, VIC, Australia) as described previously (He et al, 2015). Animal health was monitored by daily observation and weekly assessment of weight. After 5 weeks, mice were killed and tumour burden assessed by counting the number of tumour nodules within the peritoneal cavity of each mouse. Recovered tumours were fixed in formalin, embedded in paraffin and sections stained with haematoxylin and eosin (H\&E) and antibodies against WT1 (clone 6F-H2; Dako, North Sydney, NSW, Australia), CA125 (clone OC125; Roche), cytokeratin 7 (clone OV-TL 12/30; Dako), cytokeratin 20 (clone Ks20.8; Sigma-Aldrich) and p53 (clone DO-7) to evaluate tumour pathology.

Mouse PDX models. Fresh tissue was obtained from three patients undergoing surgery for suspected ovarian cancer. By analysis of a frozen section, two pathologists (SJW and JEA) identified regions of malignancy and dissected non-necrotic areas excess to diagnostic requirements for experimental use. Portions of tissue were fixed in formalin and embedded in paraffin. The remainder was mechanically disrupted in the absence of proteases and under sterile conditions passed through a size 50 stainless steel wire mesh (Sigma-Aldrich) (Bankert et al, 2011). After low speed centrifugation, the resulting pelleted cell aggregate was washed once in PBS, resuspended in PBS then injected intraperitoneally using a 23-gauge needle into four 6- to 8-week-old NSG mice (equivalent of $0.2 \mathrm{~g}$ per mouse of the pelleted cell aggregate). Injections into mice were performed within $2 \mathrm{~h}$ of tumour excision. Mice were examined weekly for intraperitoneal tumour growth. Animal health was monitored by daily observation and weekly assessment of weight. Moribund mice were killed and tumour nodules were recovered and portions processed as above for histological and immunohistochemical analysis or for further intraperitoneal xenografting in mice.

PDXs from each of the three patients were evaluated for CDCP1 expression level by immunohistochemistry as described above. Mice carrying the PDX with the highest CDCP1 expression were used to evaluate the anti-tumour effect of anti-CDCP1 antibody 10D7 (Deryugina et al, 2009). Female 6- to 8-week-old NSG mice $(n=8)$ were co-injected with cell slurry $(0.2 \mathrm{~g}$ per mouse) from the dissociated PDX and either 10D7 or isotype matched control IgG (100 $\mu$ g per mouse) as previously described (Deryugina et al, 2009). Intraperitoneal antibody treatments continued weekly at $25 \mathrm{mg} \mathrm{kg}^{-1}$ per mouse, a dose previously shown to inhibit CDCP1-mediated growth of a breast cancer cell line mouse xenograft using another anti-CDCP1 monoclonal antibody (Kollmorgen et al, 2013). Animal health was monitored by daily observation and weekly assessment of weight. After 7 weeks of treatment, mice were killed and tumour nodules counted and weighed, and ascites volume was measured.

Statistical analysis of data from in vitro and mouse assays. In vitro experiments included three replicates and were performed three times. Data are displayed as mean and standard error of the mean. For in vitro and mouse experiments, statistical significance was assessed by Student's $t$-test using the Graphpad Prism software (GraphPad, La Jolla, CA, USA). For all statistical analyses, a $P$-value of $<0.05$ was considered as significant.

\section{RESULTS}

Elevated CDCP1 expression in high-grade serous ovarian cancer. The CDCP1 protein expression was assessed by immunohistochemistry in HGSC cases, and as we have previously shown that CDCP1 is not expressed by normal ovary (He et al, 2015), we also examined its presence in normal fallopian tube $(n=8)$ and, for 
comparison, fallopian tubes from women with HGSC but no evidence of malignancy in the tube $(n=4)$, and HGSC within the fallopian tubes of patients with synchronous ovarian HGSC $(n=7)$. Of the 308 HGSC tumours examined, 292 were evaluable for CDCP1 expression, with cores of the remaining 16 cases lost during processing. No expression was observed in 67 cases $(23 \%)$, while $225(77 \%)$ showed CDCP1 positivity, with weak, moderate and strong expression noted in 133 (45.5\%), 75 (25.7\%) and 17 (5.8\%) cases, respectively. Representative images of each level of CDCP1 expression are shown in Figure 1A-D. In each specimen positive for CDCP1, its expression was exclusive to malignant cells and predominantly located on the cell surface with some cytoplasmic staining also apparent. No CDCP1 staining above background was seen in the epithelium of the eight analysed normal fallopian tubes (Figure 1E). Interestingly, two of four women with HGSC with no evident fallopian tube involvement by HGSC had areas of the tube weakly to moderately positive for CDCP1 (Figure 1F). In contrast, extensive moderate to strong CDCP1 expression was seen in HGSC within involved fallopian
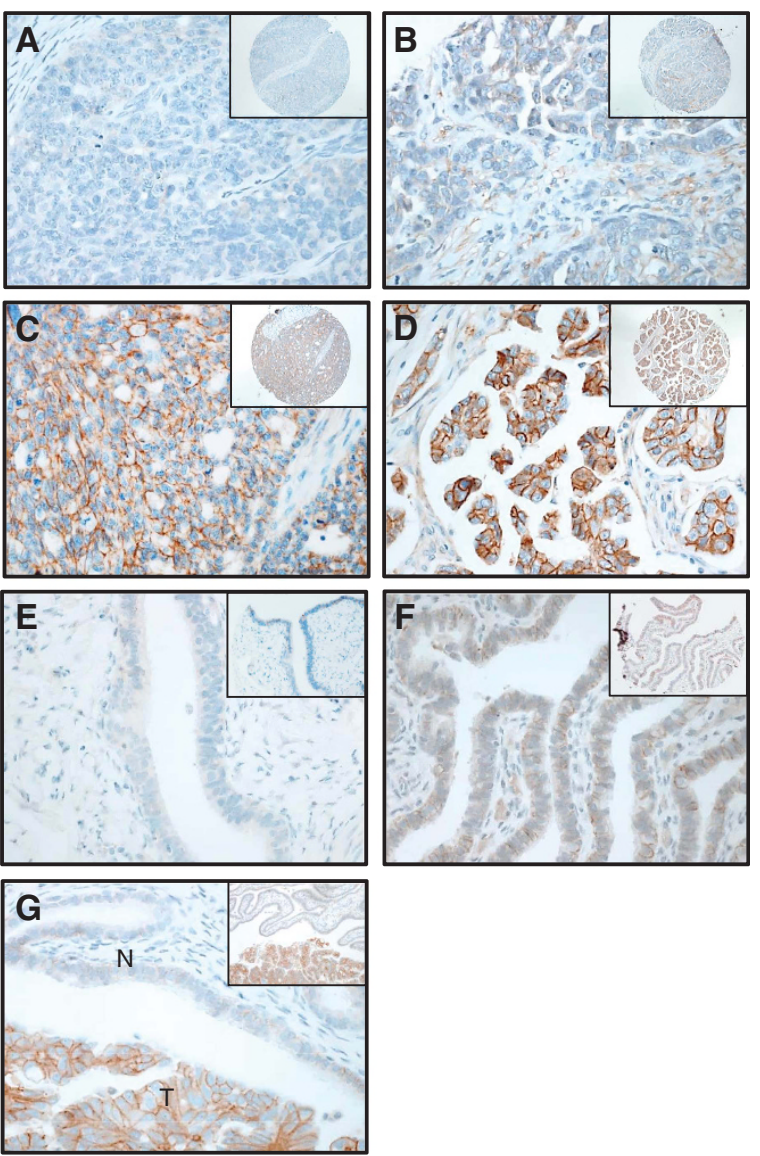

Figure 1. Immunohistochemical analysis of CDCP1 in HGSC, and normal, benign and malignant fallopian tube. (A) Negative staining of a primary HGSC tumour. (B) Weak staining of an HGSC appendiceal metastasis. (C) Moderate staining of a primary HGSC tumour. (D) Strong staining of an HGSC lymph-node metastasis. (E) Negative staining in normal fallopian tube. (F) Weak to moderate CDCP1 expression in the benign fallopian tube epithelium of a patient with HGSC in the ovary. (G) Moderate to strong CDCP1 expression in a fallopian tube showing HGSC involvement. Staining was apparent in the tumour $(T)$ and absent in the adjacent non-malignant fallopian tube (N). Magnifications: (A-D) are $\times 40$ with insets $\times 10$; $(\mathbf{E}-\mathbf{G})$ are $\times 40$ with insets $\times 20$. Scale bar is $50 \mu \mathrm{m}$. tube of six of seven cases with epithelium of adjacent nonmalignant fallopian tube negative (Figure $1 G$ ).

Kaplan-Meier analysis of the 292 cases evaluable for CDCP1 expression did not reveal any correlation between CDCP1 expression and disease-free survival or overall survival. Also, as summarised in Supplementary Table 1 there was no correlation apparent between CDCP1 expression and tumour stage. In addition to these analyses of the complete 292 patient cohort, subset analyses were performed on 104 relapsed cases for which the site of recurrence was known, and on 126 cases for correlation with TP53 mutation status. Although CDCP1 expression was not significantly correlated with any of the four sites of recurrence, a higher proportion of local (21 out of $24 ; 87.5 \%$ ) and lymphatic (12 out of $14 ; 86 \%$ ) recurrences were positive for this protein (Supplementary Table 1) compared with the total cohort (225 out of $292 ; 77 \%)$. Similarly, although there was no statistically significant correlation between TP53 mutation status and CDCP1 expression, a slightly larger proportion of TP53 null (34 out of $42 ; 81 \%$ ) mutation carriers were positive for CDCP1 (Supplementary Table 1) compared with the total cohort (225 out of $292 ; 77 \%)$.

Silencing CDCP1 expression reduces in vitro migration and non-adherent growth, without impacting adherent growth, of serous ovarian cancer cell lines. We selected the CDCP1 expressing cell lines OV90, HEY and SKOV3 to examine the function of this protein in ovarian cancer. OV90 cells exhibit morphological features and somatic loss of TP53 mutation that are characteristic of HGSC (Provencher et al, 2000). HEY cells were generated from a peritoneal deposit of a papillary cystadenocarcinoma with morphology consistent with adenocarcinoma when xenografted in mice (Buick et al, 1985). The SKOV3 line was generated from a mouse xenograft that was developed from ascites from a patient with ovarian adenocarcinoma (Fogh and Trempe, 1975). Although used widely as an ovarian cancer model, the SKOV3 cell line has recently been proposed to be poorly suited as a model for HGSC (Anglesio et al, 2013; Domcke et al, 2013; Beaufort et al, 2014). In our hands, xenografts of this line grown intraperitoneally in mice display morphology consistent with HGSC pathology (Figure 2A). In addition, consistent with the near universal mutation of the TP53 gene in HGSC patients (Ahmed et al, 2010), immunohistochemical analysis of the SKOV3 cell mouse xenograft and western blot analysis of SKOV3 cell lysates demonstrated that this line, grown in vivo or in vitro, does not express the protein (p53) translated from the TP53 gene (Figure 2B). Although WT1 staining, which characteristically shows diffuse strong nuclear positivity in $80-90 \%$ of HGSCs (Al-Hussaini et al, 2004; Kobel et al, 2008), was only weakly present in the cytoplasm of SKOV3 xenografts, immunohistochemistry for CA125 and cytokeratins 7 and 20 was consistent with HGSC pathology (Figure 2C). The strong staining observed for CA125 and cytokeratin 7 in the xenograft (Figure 2C) is consistent with patient data, which shows that ovarian cancers are almost always positive for these antigens (Mittal et al, 2008). A lack of cytokeratin 20 staining in the xenograft (Figure 2C) is consistent with data from HGSC patients, which show that all but a small number of cases do not express this antigen (Berezowski et al, 1996).

As shown in Figure 3A, stable silencing using shRNA construct V1 reduced CDCP1 expression levels by $90 \%$ in SKOV3 and HEY cells and 70\% in OV90 cells. OV90 cells predominantly express the $70-\mathrm{kDa}$ CDCP1 fragment generated through proteolytic cleavage at arginine 368 or lysine 369 of the full-length $135 \mathrm{kDa}$ protein ( $\mathrm{He}$ et al, 2010), whereas HEY and SKOV3 cells almost exclusively express $135 \mathrm{kDa}$ CDCP1. To examine the role of CDCP1, we quantified the impact of its silencing on the proliferation and migration of these cells grown under adherent conditions, and 
A

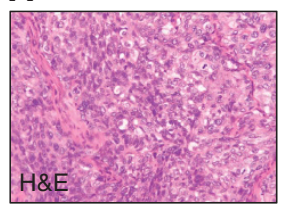

B

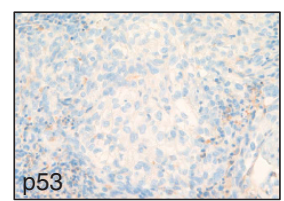

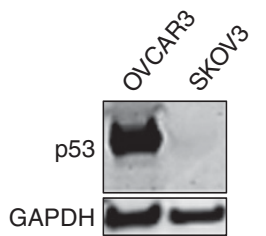

C

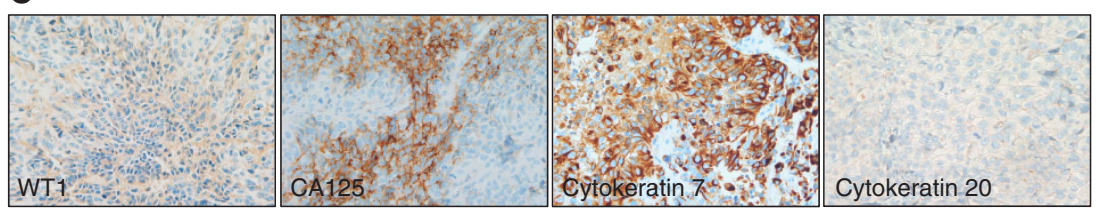

Figure 2. SKOV3 cells display HGSC features when xenografted intraperitoneally in mice and grown in vitro. (A) H\&E staining showing histology representative of a SKOV3 cell xenograft. (B) Anti-p53 immunohistochemical analysis of a SKOV3 cell xenograft showing the absence of staining within tumour cells (left). Western blot analysis of OVCAR3 and SKOV3 cell lysates for p53 (right). OVCAR3 cells carry missense-mutated TP53 that encodes p53-R248W. (C) Representative images of immunohistochemical staining of a SKOV3 cell xenograft for WT1, CA125, cytokeratin 7 and cytokeratin 20. Magnification, $\times 40$. Scale bar is $50 \mu \mathrm{m}$.

A

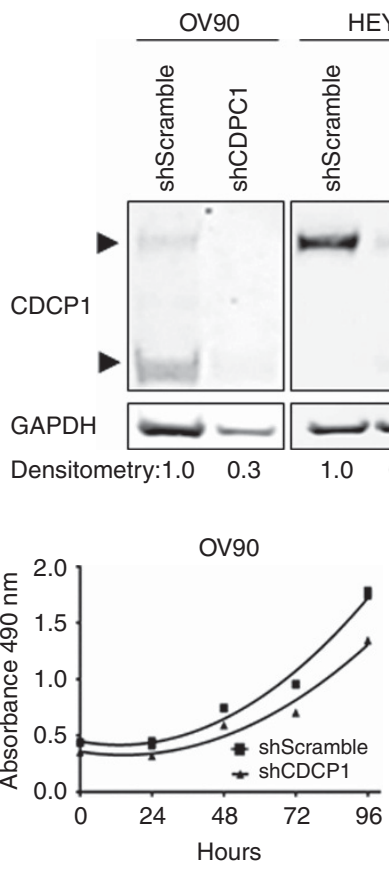

$c$

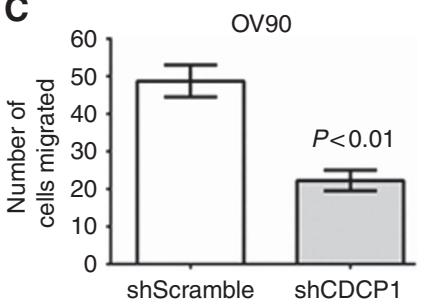

SKOV3
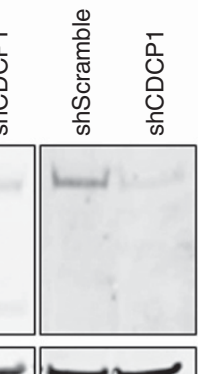

$1.0 \quad 0.1$
D

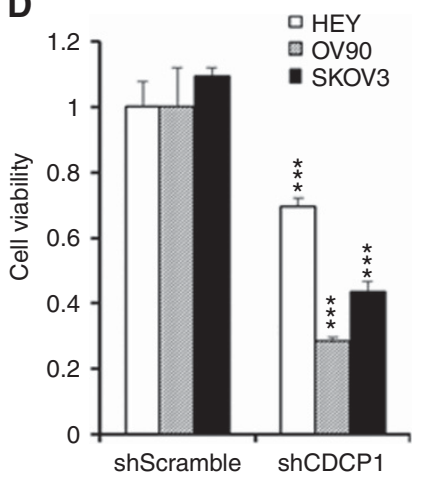

SKOV3
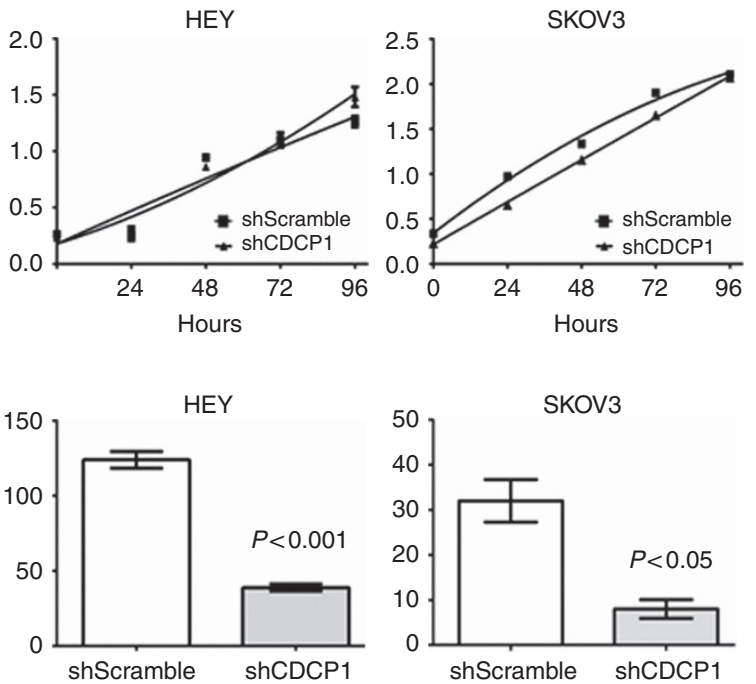

Figure 3. Silencing of CDCP1 reduces migration and non-adherent growth but not proliferation of ovarian cancer cell lines in vitro. (A) AntiCDCP1 and -GAPDH western blot analysis of OV90, HEY and SKOV3 lysates of cells stably transduced with lentivirus carrying the CDCP1 targeting sequence V1 or scramble control shRNA. Densitometric analysis of the CDCP1 signal, determined from three independent western blot analyses, is shown at the bottom of the panel. (B) Adherent cell growth. Cells (2000 per well) were seeded and at the indicated time points absorbance was read at $490 \mathrm{~nm}$. Absorbance was measured each day for 4 days. (C) Comparison of migration of OV90, HEY and SKOV3 cells stably transduced with a scramble control or a CDCP1 shRNA. Cells (50000 per well) seeded in serum-free media migrated towards a 10\% FCS gradient.

(D) Non-adherent cell growth. Cells (8000 per well) were seeded in serum-free media in wells of an ultra-low attachment plate and after $72 \mathrm{~h}$ cell viability was assessed. ${ }^{\star \star \star} P<0.001$. Data points represent mean and standard error of the mean from three independent experiments, each with triplicate wells for each time point. 
growth under non-adherent conditions. As shown in Figure 3B, silencing of CDCP1 had no statistically significant impact on proliferation of OV90, HEY and SKOV3 cells over 4 days. In contrast, using a transwell migration assay we saw statistically significant impacts on the ability of these cells to migrate towards FCS as chemo-attractant over a 48 -h period (Figure $3 \mathrm{C}$ ). The number of migrated cells reduced by $\sim 60 \%, \sim 68 \%$ and $\sim 75 \%$ for OV90, HEY and SKOV3 cells, respectively. In addition, silencing of CDCP1 reduced the non-adherent growth of OV90, HEY and SKOV3 cells after $72 \mathrm{~h}$ by $\sim 30 \%, 70 \%$ and $60 \%$, respectively (Figure 3D). The observed effects of CDCP1 silencing on migration of adherent cells, and growth of non-adherent cells were also observed with a second shRNA construct, V2, against CDCP1 (Supplementary Figure S1). These data suggest that CDCP1 is involved in ovarian cancer cell migration and non-adherent growth, which are processes crucial for dissemination of this malignancy (Lengyel, 2010).

Silencing of CDCP1 reduces intraperitoneal tumour formation of SKOV3 cells in mice. To examine whether targeting CDCP1 can reduce ovarian tumour burden in vivo, we evaluated the impact of silencing CDCP1 on the ability of SKOV3 cells to grow as intraperitoneal xenografts in mice. Mice were injected intraperitoneally with luciferase-labelled SKOV3-shCDCP1 or SKOV3-shScramble cells, and tumour formation was monitored weekly by bioluminescent imaging up to the time of killing of mice after 5 weeks. As shown in Figure 4A, bioluminescent imaging indicated that tumour burden in mice injected with SKOV3 cells silenced for CDCP1 (SKOV3-shCDCP1) was much lower than in mice that received control SKOV3-shScramble cells. At the time of killing the mice, tumour nodules were dispersed throughout the peritoneal cavity with quantitative analysis, indicating that there were $\sim 82 \%$ fewer SKOV3-shCDCP1 than control SKOV3shScramble tumours (Figure $4 \mathrm{~B}$ ). To interrogate pathways that are mediated by CDCP1 in SKOV3 xenografts, we performed western blot analysis for activation of $\mathrm{Src}$, a pathway previously shown by us and others to be important in transducing pro-cancer effects mediated by CDCP1 in in vitro systems (He et al, 2010; Miyazawa et al, 2010; Wortmann et al, 2011; Benes et al, 2012; Kollmorgen et al, 2012) and mouse models of melanoma (Liu et al, 2011) and prostate cancer (Casar et al, 2012). As shown in Figure 4C, CDCP1 levels that were observed in cultured SKOV3shCDCP1 and -shScramble cells were maintained in xenograft tumours recovered from mice. Activation of Src was robust in SKOV3-shScramble tumours, but barely detectable in SKOV3shCDCP1 tumours (Figure 4C). Consistent with these in vivo data, examination of p-SrcY416 levels in SKOV3-shCDCP1 and shScramble cells grown in vitro indicated that Src activation was unaffected by silencing of CDCP1 in SKOV3 cells under adherent conditions, but it was markedly reduced in SKOV3-shCDCP1 compared with SKOV3-shScramble cells under non-adherent conditions (Supplementary Figure S2). Together, these data indicate that CDCP1 is important in an in vivo model of ovarian cancer and that it is required for signalling via Src in tumours in vivo, and in vitro in cells under non-adherent growth conditions.

Antibody targeting of CDCP1 reduces in vitro migration and non-adherent, but not adherent growth, of ovarian cancer cell lines. We next assessed the impact in vitro, on OV90, HEY and SKOV3 cells, of directly targeting CDCP1 using a function blocking monoclonal antibody, 10D7 (Deryugina et al, 2009; Casar et al, 2012; He et al, 2015), examining its impact on cell growth under adherent and non-adherent conditions, and cell migration. The data obtained from in vitro assays were broadly consistent with results seen when CDCP1 was silenced (Figure 3B-D). As shown in Figure 5A and B, while 10D7 had no impact on adherent growth of the three cell lines, it reduced non-adherent growth of OV90, HEY and SKOV3 cells by $\sim 15 \%, \sim 18 \%$ and
A
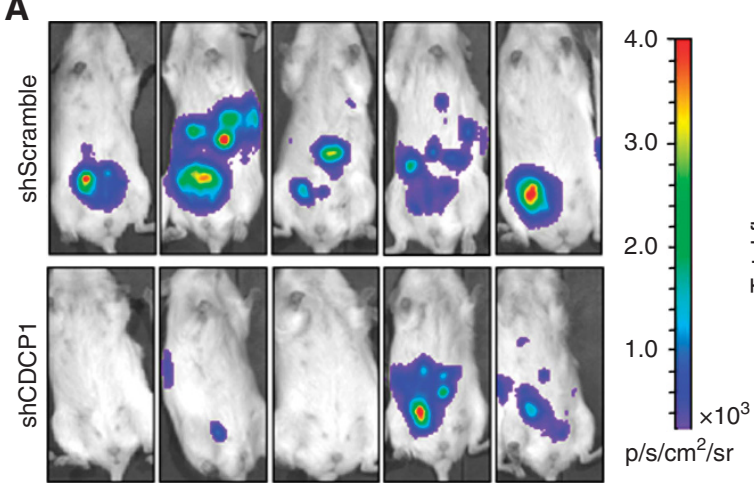

B
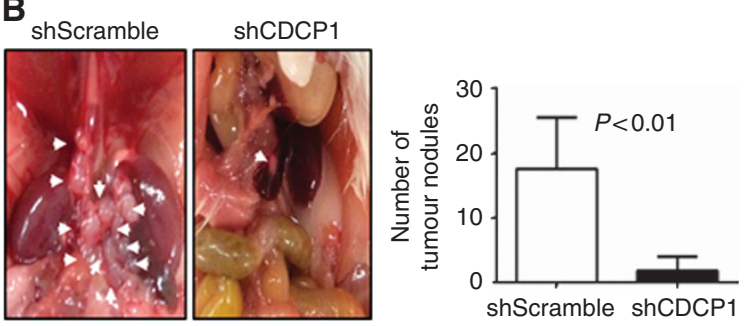

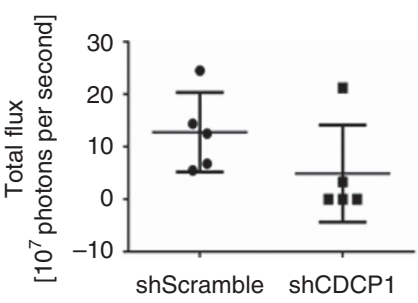

C

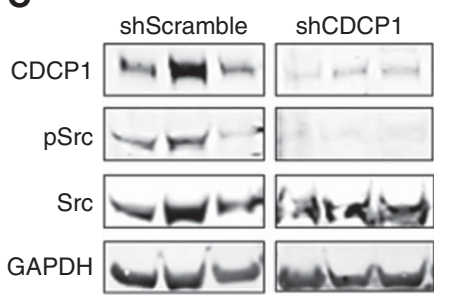

Figure 4. Silencing of CDCP1 reduces intraperitoneal tumour formation of SKOV3 cells in mice. Female NSG mice were injected with SKOV3shScramble $(n=5)$ or SKOV3-shCDCP1 $(n=5)$ cells $\left(5 \times 10^{6}\right)$. (A) Left, Bioluminescent images of mice after 5 weeks of tumour growth. Right, Graph of the bioluminescent signal (total flux; photons per seconds) obtained from each mouse. (B) Left, Representative images of the peritoneal cavity of mice at the time of killing at 5 weeks after injection of SKOV3-shScramble or SKOV3-shCDCP1 cells. Arrows indicate tumour nodules. Right, Graph of the number of peritoneal tumour nodules present in mice injected with either SKOV3-shScramble or SKOV3-shCDCP1 cells. Data represent mean and standard deviation of each group. (C) Western blot analysis of lysates from three randomly selected SKOV3-shScramble and SKOV3shCDCP1 xenograft tumours recovered from mice for CDCP1, p-Src-Y416 (pSrc), Src and GAPDH. 

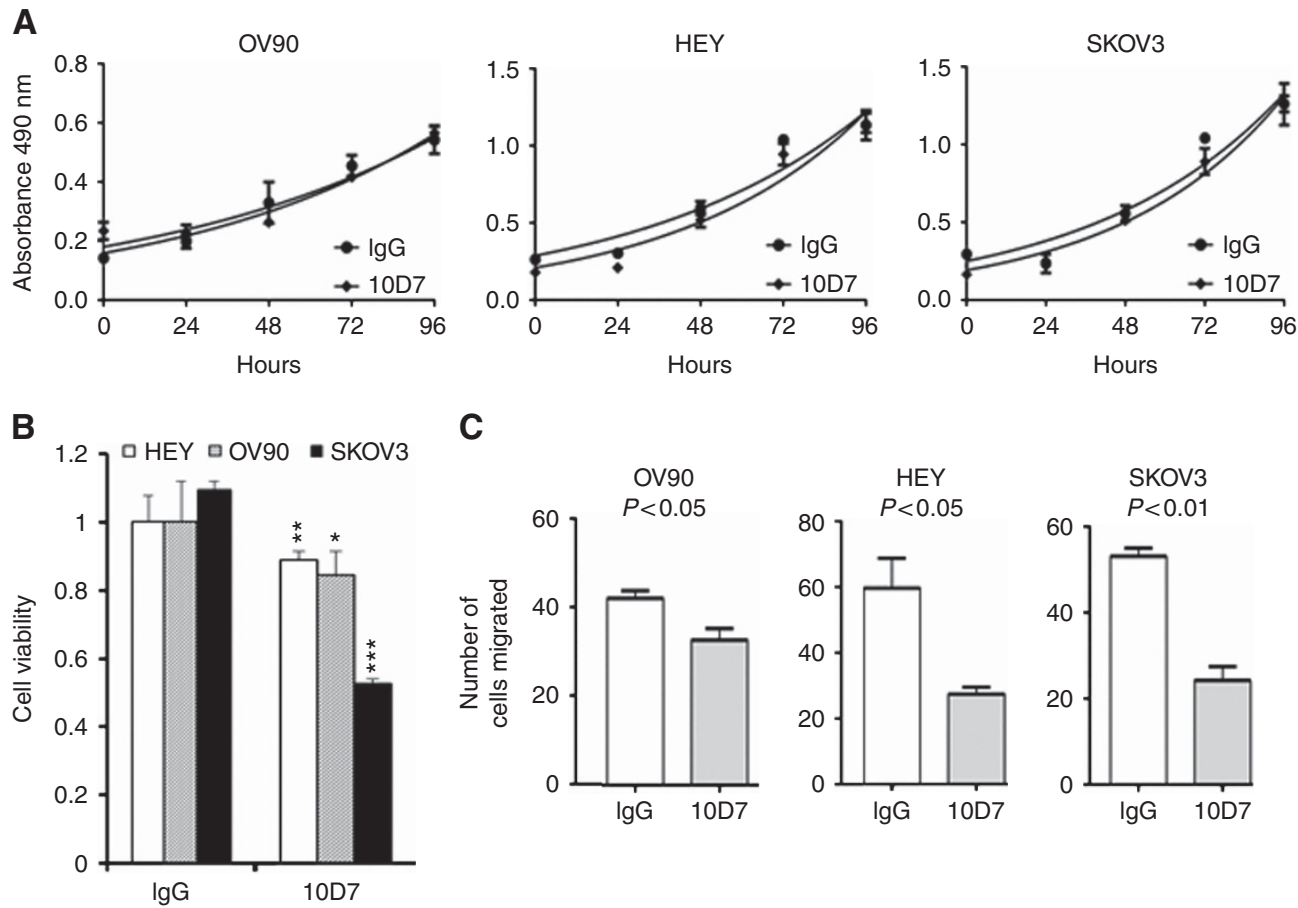

C
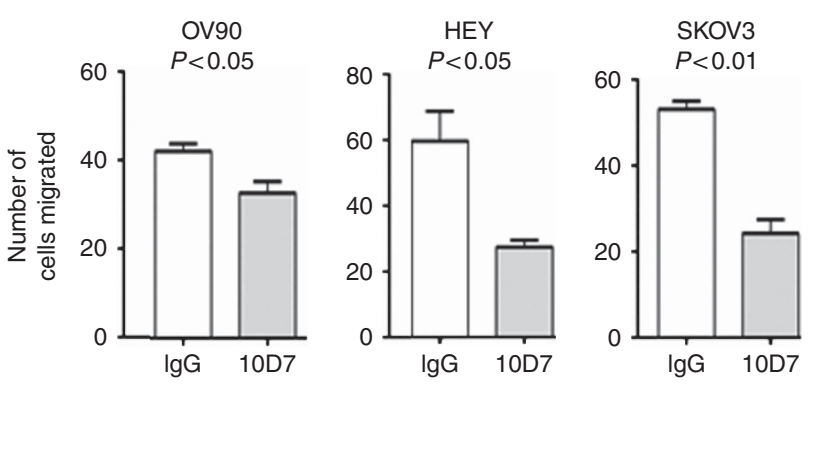

Figure 5. Targeting CDCP1 with monoclonal antibody 10D7 reduces in vitro migration and non-adherent, but not adherent growth, of ovarian cancer cell lines. (A) Adherent cell growth. Cells (2000 per well) were seeded in media containing antibody $\left.10 \mathrm{D} 7 \mathrm{or} \mathrm{control} \mathrm{lgG} \mathrm{(50} \mu \mathrm{g} \mathrm{ml}^{-1}\right)$ and at the indicated times absorbance was read at $490 \mathrm{~nm}$. Absorbance was measured each day for 4 days. (B) Non-adherent cell growth. Cells (8000 per well) were seeded in serum-free media containing 10D7 or control lgG $\left(50 \mu \mathrm{g} \mathrm{ml}^{-1}\right)$ in wells of an ultra-low attachment plate and after $72 \mathrm{~h}$ cell viability was assessed. ${ }^{\star} P<0.05 ;{ }^{\star \star} P<0.01 ;{ }^{* \star} P<0.001$. (C) Comparison of migration of OV90, HEY and SKOV3 cells (50 000 per well) seeded in serum-free media containing antibody $10 \mathrm{D} 7$ or control lgG $\left(50 \mu \mathrm{g} \mathrm{ml}^{-1}\right)$ migrated towards $10 \% \mathrm{FCS}$ containing $10 \mathrm{D} 7$ or control lgG $\left(50 \mu \mathrm{g} \mathrm{ml}^{-1}\right)$. Data points represent mean and standard error of the mean from three independent experiments, each with triplicate wells for each time point.

$\sim 50 \%$, respectively. In addition, treatments with $10 \mathrm{D} 7$ reduced migration of OV90, HEY and SKOV3 cells by $\sim 20 \%, \sim 55 \%$ and $\sim 60 \%$, respectively (Figure $5 \mathrm{C}$ ).

Monoclonal antibody targeting of CDCP1 impedes HGSC PDX growth. To examine the impact of targeting CDCP1 in vivo, we established PDX models of HGSC with the intention of challenging the highest CDCP1 expressing xenograft with the function blocking monoclonal antibody 10D7. Compared with mouse xenograft models of ovarian cancer cell lines, PDX models more accurately recapitulate patient tumours in terms of response to chemotherapy, and histologic and molecular features (Scott et al, 2014). As shown in Figure 6A, the three developed PDXs displayed the morphological features and CDCP1 expression level of the corresponding HGSC patient tumour. Relative to the staining intensities observed in the 292 HGSC cases analysed above, CDCP1 expression levels were moderate, strong and none for the tumour and PDX for patients 7, 28 and 36, respectively (Figure 6A). We selected the PDX with the highest expression of CDCP1 (PDX-28) to evaluate the impact of antibody 10D7 on HGSC. Mimicking disease in patients, tumours of PDX-28 were dispersed throughout the peritoneal cavity as nodules on uterus, spleen, liver and diaphragm (Figure 6B). Quantitative analysis indicated that $10 \mathrm{D} 7$ treatment reduced on average the total number of tumours by $\sim 45 \%$, the weight of the largest tumour by $\sim 60 \%$ and the combined weight of tumours by $25 \%$ (Figure $6 \mathrm{C}$ ). In addition, we noted that two mice from the control IgG group developed a small volume of ascites, which was not seen in any of the 10D7-treated group. Consistent with analysis of xenograft tumours silenced for CDCP1, there was a marked difference in signalling via Src in 10D7- vs IgG-treated PDX-28. As shown in Figure 6D, western blot analysis demonstrated that phosphorylation of Src-Y416 was consistently much lower in 10D7- vs IgG- treated tumours. Throughout the 7-week treatment period, no toxicity due to 10D7 treatment was observed as assessed by changes in mouse weight and general health relative to IgG-treated animals (data not shown). These data indicate that antibody targeting of CDCP1 is effective at inhibiting growth of an HGSC PDX that has high levels of CDCP1 expression and that this inhibition reduces signalling via Src.

\section{DISCUSSION}

Here, we demonstrate that the cell-surface protein CDCP1 has an important and targetable role in HGSC. CUB-domain containing protein 1 is expressed by $77 \%$ of 292 analysed HGSC cases and blockade of this protein, either via silencing or antibody-mediated functional inhibition, markedly reduces progression of HGSC in mouse models. We have previously shown that CDCP1 is not expressed by the normal ovary (He et al, 2015), and our analysis in this study indicates that this protein is not expressed by normal fallopian tube. As our immunohistochemical analysis demonstrated that CDCP1 is predominantly located on the cell surface where it is accessible to therapeutic antibodies, these findings suggest that this protein will be able to be selectively targeted in the majority of HGSC patients without impacting on normal cells and structures.

Data from our in vitro and mouse models indicate that CDCP1 is functionally important in processes required for progression of HGSC, and that mechanistically its role in HGSC involves activation of Src. In terms of the processes required for progression of HGSC, our in vitro assays indicate that CDCP1 is involved in migration and non-adherent, but not adherent, growth of ovarian cancer cells. We observed that silencing of CDCP1 expression 
A

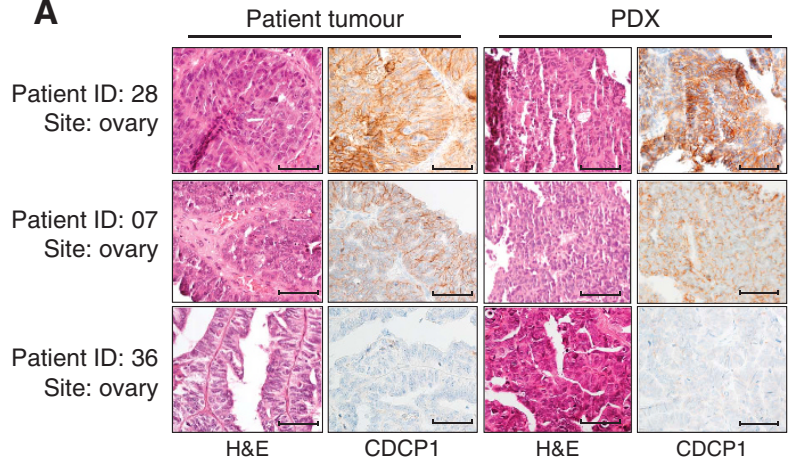

B
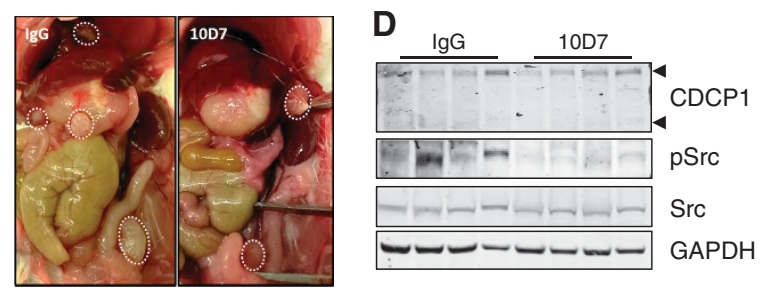

C
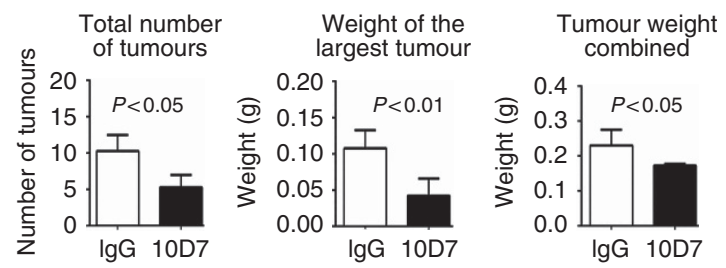

Figure 6. Monoclonal antibody targeting of CDCP1 impedes HGSC PDX growth. (A) H\&E and anti-CDCP1 (brown) staining of three patient tumours and PDXs developed from these tumours. Magnification, $\times 40$. CDCP1 is expressed by malignant cells, detected mainly in the membrane with cytosolic staining also apparent. Scale bar is $50 \mu \mathrm{m}$. (B-D) Mice were injected with cell slurry from the PDX of patient 28 along with antibody 10D7 or isotype matched control lgG (100 $\mu \mathrm{g})$. $10 \mathrm{D} 7$ and $\mathrm{lgG}$ treatments continued weekly at $25 \mathrm{mg} \mathrm{kg}^{-1}$ per mouse ( $n=4$ mice per treatment). (B) Representative images, at the time of killing of mice at week 7, of the peritoneal cavity of mice treated with IgG (left) or 10D7 (right). (C) Graphical representation of the total number of tumours (left), the weight of the largest tumour (middle) and the weight of all tumours combined (right) of groups of mice treated with $\operatorname{lgG}$ or 10D7. Data represent mean and standard deviation of each group. (D) Western blot analysis of lysates from four randomly selected IgG- and 10D7-treated PDX tumours recovered from mice. Lysates were examined for CDCP1, p-Src-Y416 (pSrc), Src and GAPDH.

reduced in vitro migration of the three ovarian cancer lines OV90, HEY and SKOV3 by at least $60 \%$, which was consistent with our previous reports, indicating that cell-surface CDCP1 is likely to be directly involved in migration in vitro of ovarian cancer cells (Dong et al, 2012; Adams et al, 2015). Our finding that CDCP1 is not involved in proliferation under adherent conditions of OV90, HEY and SKOV3 cells, is also consistent with studies of gastric cancer (Uekita et al, 2008) and ovarian clear cell carcinoma (He et al, 2015) cell lines. As resistance to anoikis is a critical feature of highly aggressive ovarian cancer cells (Cai et al, 2015), and is thought to be essential for peritoneal dissemination in patients (Lengyel, 2010), we also explored the role of CDCP1 in the growth of non-adherent cells. Data for OV90, HEY and SKOV3 cells indicated that CDCP1 is important in resistance to anoikis, as its silencing and blockade using antibody 10D7 markedly reduced the viability of each of these lines under non-adherent conditions. Consistent with these in vitro data, results from our intraperitoneal model of ovarian cancer showed that silencing of CDCP1 reduced tumour formation of SKOV3 cells in mice by $\sim 82 \%$.

Although immunohistochemical analysis demonstrated that CDCP1 expression is elevated in the majority of HGSC cases, we saw no correlation between increased CDCP1 levels in patient samples and clinical parameters, including disease-free and overall survival, tumour stage, site of recurrence or TP53 mutation status. As correlation with clinical parameters can indicate that the biological function of a protein is required for disease progression, we used a clinically relevant mouse model to further examine whether CDCP1 is functionally important in HGSC. For this purpose, we developed three intraperitoneal PDX mouse models with histological and immunohistochemical analysis revealing that for each patient tumour, HGSC morphology and CDCP1 expression level were retained in the corresponding PDX. Employing the PDX with the highest CDCP1 expression, the function blocking anti-CDCP1 antibody 10D7 (Deryugina et al, 2009; Casar et al, 2012; He et al, 2015) caused a significant reduction in HGSC tumour burden. Importantly, western blot analyses suggest that mechanistically the ability of CDCP1 to promote growth of non-adherent HGSC cells in vitro, and growth in vivo of cell line xenograft and PDX models of ovarian cancer, is mediated by activation of Src. This observation is consistent with very recent (Leroy et al, 2015) and earlier (Miyazawa et al, 2010; Liu et al, 2011; Wortmann et al, 2011; Benes et al, 2012; Casar et al, 2012; Kollmorgen et al, 2012; He et al, 2015) reports showing that $\mathrm{CDCP} 1$ has a key role in cancer by promoting activation of Src family kinases.

In this study, we employed the ovarian cancer cell line SKOV3 in both in vitro and mouse assays to evaluate the role of CDCP1 in HGSC. Interestingly, despite being used extensively as a model for ovarian cancer, and although the immuno-phenotype of SKOV3 cells most closely resembles the profile seen in HGSC patients (Anglesio et al, 2013), it has recently been proposed that this line is poorly suited as a model for this malignancy (Anglesio et al, 2013; Domcke et al, 2013; Beaufort et al, 2014). Accordingly, in the current study we evaluated the extent to which the morphological features and biomarker expression profile of SKOV3 cells are characteristic of HGSC. We observed that mouse xenografts of SKOV3 cells display characteristic HGSC morphology and expression of the markers CA125, and cytokeratins 7 and 20 (Berezowski et al, 1996; Mittal et al, 2008). In contrast, we noted that although the majority of HGSC patient tumours display nuclear expression of the marker WT1 (Al-Hussaini et al, 2004; Kobel et al, 2008), the SKOV3 cell xenograft only showed weak cytoplasmic staining for this antigen. However, further support that SKOV3 cells display HGSC characteristics came from our analysis of the expression of p53. The TP53 gene that encodes this protein is mutated in nearly all HGSC patients (Ahmed et al, 2010). By western blot and immunohistochemical analysis, we demonstrated that the SKOV3 cells used in our study do not express p53 in vitro or in vivo. Consistent with our findings, western blot analysis by another laboratory of SKOV3 cells, obtained from the National Cancer Institute Cell Repository, showed that this line does not express p53 (Desjardins et al, 2014). Furthermore, the Catalogue of Somatic Mutations in Cancer (COSMIC) database (Forbes et al, 2008) indicates that SKOV3 cells carry a homozygous deletion in the TP53 gene at cytosine 267 . This causes a frameshift in the coding sequence that converts serine at position 90 to a proline, with truncation of the p53 protein after another 33 amino acids. Another recent report has evaluated the experimental utility of SKOV3 cells as a model for HGSC and noted TP53 mutation and loss of p53 expression by this cell line (Elias et al, 2015). On balance, our data indicate that SKOV3 cell xenografts in mice display features of HGSC, and are useful for assisting in evaluating the role of CDCP1 and other proteins in this malignancy. Also, similar to the proposal of 
Elias et al (2015), our data indicate that selection of cell lines suitable for study of HGSC requires not only a consideration of genetic features, but also anatomic, immunohistological and clinical features.

In summary, our data demonstrate that the cell-surface receptor CDCP1 is expressed by the majority of HGSC tumours, but not by normal cells of the ovary and fallopian tube. We have also shown that CDCP1 is functionally important in this cancer, and its blockade reduces migration and non-adherent growth of ovarian cancer cell lines in vitro, and growth of both mouse xenografts of ovarian cancer cell lines and an HGSC PDX. These data indicate that therapeutic humanised antibodies against CDCP1 may be useful against HGSC tumours or such reagents may be useful for the targeted delivery of cytotoxic agents to this malignancy. Further work is required to define the molecular mechanisms beyond Src activation, by which CDCP1 promotes HGSC and the pathways that are impacted by the function inhibiting anti-CDCP1 antibody 10D7.

\section{ACKNOWLEDGEMENTS}

We are grateful to Kristen Gibbons, Mater Research, for assistance with statistical analysis. We thank Dr Kathy Roby, University of Kansas Medical Center, for providing the OV90 cell line. This work was supported by grants to JDH from the Cancer Council Queensland (1021827, 1045801 and 1082040). BSH is the recipient of a University of Queens and Post-Graduate Award. MNA is the recipient of an Australian Post-Graduate Award. JDH is an Australian Research Council Future Fellow (FT120100917). The Gynaecological Oncology Biobank at Westmead is a member of the Australasian Biospecimen Network-Oncology group, which was funded by the National Health and Medical Research Council Enabling grants 310670 and 628903 and Cancer Institute NSW grant 12/RIG/1-17.

\section{CONFLICT OF INTEREST}

$\mathrm{JDH}$ is an inventor on a patent describing CDCP1 as an anticancer target.

\section{REFERENCES}

Adams MN, Harrington BS, He Y, Davies CM, Wallace SJ, Chetty NP, Crandon AJ, Oliveira NB, Shannon CM, Coward JI, Lumley JW, Perrin LC, Armes JE, Hooper JD (2015) EGF inhibits constitutive internalization and palmitoylation-dependent degradation of membranespanning procancer $\mathrm{CDCP} 1$ promoting its availability on the cell surface. Oncogene 34(11): 1375-1383.

Ahmed AA, Etemadmoghadam D, Temple J, Lynch AG, Riad M, Sharma R, Stewart C, Fereday S, Caldas C, Defazio A, Bowtell D, Brenton JD (2010) Driver mutations in TP53 are ubiquitous in high grade serous carcinoma of the ovary. J Pathol 221(1): 49-56.

Al-Hussaini M, Stockman A, Foster H, McCluggage WG (2004) WT-1 assists in distinguishing ovarian from uterine serous carcinoma and in distinguishing between serous and endometrioid ovarian carcinoma. Histopathology 44(2): 109-115.

Anglesio MS, Wiegand KC, Melnyk N, Chow C, Salamanca C, Prentice LM, Senz J, Yang W, Spillman MA, Cochrane DR, Shumansky K, Shah SP, Kalloger SE, Huntsman DG (2013) Type-specific cell line models for type-specific ovarian cancer research. PLoS One 8(9): e72162.

Armes JE, Davies CM, Wallace S, Taheri T, Perrin LC, Autelitano DJ (2013) AGR2 expression in ovarian tumours: a potential biomarker for endometrioid and mucinous differentiation. Pathology 45(1): 49-54.

Awakura Y, Nakamura E, Takahashi T, Kotani H, Mikami Y, Kadowaki T, Myoumoto A, Akiyama H, Ito N, Kamoto T, Manabe T, Nobumasa H, Tsujimoto G, Ogawa O (2008) Microarray-based identification of CUB-domain containing protein 1 as a potential prognostic marker in conventional renal cell carcinoma. J Cancer Res Clin Oncol 134(12): $1363-1369$.

Bankert RB, Balu-Iyer SV, Odunsi K, Shultz LD, Kelleher Jr RJ, Barnas JL, Simpson-Abelson M, Parsons R, Yokota SJ (2011) Humanized mouse model of ovarian cancer recapitulates patient solid tumor progression, ascites formation, and metastasis. PLoS One 6(9): e24420.

Beaufort CM, Helmijr JC, Piskorz AM, Hoogstraat M, Ruigrok-Ritstier K, Besselink N, Murtaza M, van IWF, Heine AA, Smid M, Koudijs MJ, Brenton JD, Berns EM, Helleman J (2014) Ovarian cancer cell line panel (OCCP): clinical importance of in vitro morphological subtypes. PLoS One 9(9): e103988.

Benes CH, Poulogiannis G, Cantley LC, Soltoff SP (2012) The SRC-associated protein CUB Domain-Containing Protein-1 regulates adhesion and motility. Oncogene 31(5): 653-663.

Berezowski K, Stastny JF, Kornstein MJ (1996) Cytokeratins 7 and 20 and carcinoembryonic antigen in ovarian and colonic carcinoma. Mod Pathol 9(4): 426-429.

Buick RN, Pullano R, Trent JM (1985) Comparative properties of five human ovarian adenocarcinoma cell lines. Cancer Res 45(8): 3668-3676.

Cai Q, Yan L, Xu Y (2015) Anoikis resistance is a critical feature of highly aggressive ovarian cancer cells. Oncogene 34(25): 3315-3324.

Casar B, He Y, Iconomou M, Hooper JD, Quigley JP, Deryugina EI (2012) Blocking of CDCP1 cleavage in vivo prevents Akt-dependent survival and inhibits metastatic colonization through PARP1-mediated apoptosis of cancer cells. Oncogene 31(35): 3924-3938.

Casar B, Rimann I, Kato H, Shattil SJ, Quigley JP, Deryugina EI (2014) In vivo cleaved CDCP1 promotes early tumor dissemination via complexing with activated beta1 integrin and induction of FAK/PI3K/Akt motility signaling. Oncogene 33(2): 255-268.

Coleman RL, Monk BJ, Sood AK, Herzog TJ (2013) Latest research and treatment of advanced-stage epithelial ovarian cancer. Nat Rev Clin Oncol 10(4): 211-224.

Derycke MS, Pambuccian SE, Gilks CB, Kalloger SE, Ghidouche A, Lopez M, Bliss RL, Geller MA, Argenta PA, Harrington KM, Skubitz AP (2010) Nectin 4 overexpression in ovarian cancer tissues and serum: potential role as a serum biomarker. Am J Clin Pathol 134(5): 835-845.

Deryugina EI, Conn EM, Wortmann A, Partridge JJ, Kupriyanova TA, Ardi VC, Hooper JD, Quigley JP (2009) Functional role of cell surface CUB domain-containing protein 1 in tumor cell dissemination. Mol Cancer Res 7(8): 1197-1211.

Desjardins M, Xie J, Gurler H, Muralidhar GG, Sacks JD, Burdette JE, Barbolina MV (2014) Versican regulates metastasis of epithelial ovarian carcinoma cells and spheroids. J Ovarian Res 7: 70.

Domcke S, Sinha R, Levine DA, Sander C, Schultz N (2013) Evaluating cell lines as tumour models by comparison of genomic profiles. Nat Commun 4: 2126.

Dong Y, He Y, de Boer L, Stack MS, Lumley JW, Clements JA, Hooper JD (2012) The cell surface glycoprotein CUB domain-containing protein 1 (CDCP1) contributes to epidermal growth factor receptor-mediated cell migration. J Biol Chem 287(13): 9792-9803.

Elias KM, Emori MM, Papp E, MacDuffie E, Konecny GE, Velculescu VE, Drapkin R (2015) Beyond genomics: Critical evaluation of cell line utility for ovarian cancer research. Gynecol Oncol 139(1): 97-103.

Emerling BM, Benes CH, Poulogiannis G, Bell EL, Courtney K, Liu H, Choo-Wing R, Bellinger G, Tsukazawa KS, Brown V, Signoretti S, Soltoff SP, Cantley LC (2013) Identification of CDCP1 as a hypoxia-inducible factor 2alpha (HIF-2alpha) target gene that is associated with survival in clear cell renal cell carcinoma patients. Proc Natl Acad Sci USA 110(9): 3483-3488.

Emmanuel C, Chiew YE, George J, Etemadmoghadam D, Anglesio MS, Sharma R, Russell P, Kennedy C, Fereday S, Hung J, Galletta L, Hogg R, Wain GV, Brand A, Balleine R, MacConaill L, Palescandolo E, Hunter SM, Campbell I, Dobrovic A, Wong SQ, Do H, Clarke CL, Harnett PR, Bowtell DD, deFazio A (2014) Genomic classification of serous ovarian cancer with adjacent borderline differentiates RAS pathway and TP53-mutant tumors and identifies NRAS as an oncogenic driver. Clin Cancer Res 20(24): 6618-6630.

Ferlay J, Soerjomataram I, Dikshit R, Eser S, Mathers C, Rebelo M, Parkin DM, Forman D, Bray F (2015) Cancer incidence and mortality worldwide: sources, methods and major patterns in GLOBOCAN 2012. Int J Cancer 136(5): E359-E386.

Fogh J, Trempe G (1975) New human tumor cell lines. In Human Tumor Cells in Vitro, Fogh J (ed.). Plenum Press: New York, pp 115-159. 
Forbes SA, Bhamra G, Bamford S, Dawson E, Kok C, Clements J, Menzies A, Teague JW, Futreal PA, Stratton MR (2008) The Catalogue of Somatic Mutations in Cancer (COSMIC). Curr Protoc Hum Genet. Chapter 10, Unit 10.11 .

Fukuchi K, Steiniger SC, Deryugina E, Liu Y, Lowery CA, Gloeckner C, Zhou B, Kaufmann GF, Quigley JP, Janda KD (2010) Inhibition of tumor metastasis: functional immune modulation of the CUB domain containing protein 1. Mol Pharm 7(1): 245-253.

Gao W, Chen L, Ma Z, Du Z, Zhao Z, Hu Z, Li Q (2013) Isolation and phenotypic characterization of colorectal cancer stem cells with organ-specific metastatic potential. Gastroenterology 145(3): 636-46 e5.

Gilks CB, Irving J, Kobel M, Lee C, Singh N, Wilkinson N, McCluggage WG (2015) Incidental nonuterine high-grade serous carcinomas arise in the fallopian tube in most cases: further evidence for the tubal origin of highgrade serous carcinomas. Am J Surg Pathol 39(3): 357-364.

He Y, Wortmann A, Burke LJ, Reid JC, Adams MN, Abdul-Jabbar I, Quigley JP, Leduc R, Kirchhofer D, Hooper JD (2010) Proteolysis-induced $\mathrm{N}$-terminal ectodomain shedding of the integral membrane glycoprotein CUB domain-containing protein 1 (CDCP1) is accompanied by tyrosine phosphorylation of its C-terminal domain and recruitment of Src and PKCdelta. J Biol Chem 285(34): 26162-26173.

He Y, Wu AC, Harrington BS, Davies CM, Wallace SJ, Adams MN, Palmer JS, Roche DK, Hollier BG, Westbrook TF, Hamidi H, Konecny GE, Winterhoff B, Chetty NP, Crandon AJ, Oliveira NB, Shannon CM, Tinker AV, Gilks CB, Coward JI, Lumley JW, Perrin LC, Armes JE, Hooper JD (2015) Elevated $\mathrm{CDCP} 1$ predicts poor patient outcome and mediates ovarian clear cell carcinoma by promoting tumor spheroid formation, cell migration and chemoresistance. Oncogene. (accepted for publication).

Hooper JD, Zijlstra A, Aimes RT, Liang H, Claassen GF, Tarin D, Testa JE, Quigley JP (2003) Subtractive immunization using highly metastatic human tumor cells identifies SIMA135/CDCP1, a $135 \mathrm{kDa}$ cell surface phosphorylated glycoprotein antigen. Oncogene 22(12): 1783-1794.

Ikeda J, Oda T, Inoue M, Uekita T, Sakai R, Okumura M, Aozasa K, Morii E (2009) Expression of CUB domain containing protein (CDCP1) is correlated with prognosis and survival of patients with adenocarcinoma of lung. Cancer Sci 100(3): 429-433.

Kim J, Coffey DM, Creighton CJ, Yu Z, Hawkins SM, Matzuk MM (2012) High-grade serous ovarian cancer arises from fallopian tube in a mouse model. Proc Natl Acad Sci USA 109(10): 3921-3926.

Kobel M, Kalloger SE, Boyd N, McKinney S, Mehl E, Palmer C, Leung S, Bowen NJ, Ionescu DN, Rajput A, Prentice LM, Miller D, Santos J, Swenerton K, Gilks CB, Huntsman D (2008) Ovarian carcinoma subtypes are different diseases: implications for biomarker studies. PLoS Med 5(12): e232.

Kobel M, Reuss A, Bois A, Kommoss S, Kommoss F, Gao D, Kalloger SE, Huntsman DG, Gilks CB (2010) The biological and clinical value of p53 expression in pelvic high-grade serous carcinomas. J Pathol 222(2): 191-198.

Kollmorgen G, Bossenmaier B, Niederfellner G, Haring HU, Lammers R (2012) Structural requirements for cub domain containing protein 1 (CDCP1) and Src dependent cell transformation. PLoS One 7(12): e53050.

Kollmorgen G, Niederfellner G, Lifke A, Spohn GJ, Rieder N, Harring SV, Bauss F, Burtscher H, Lammers R, Bossenmaier B (2013) Antibody mediated CDCP1 degradation as mode of action for cancer targeted therapy. Mol Oncol 7(6): 1142-1151.

Kumar B, De Silva M, Venter DJ, Armes JE (2004) Tissue microarrays: a practical guide. Pathology 36(4): 295-300.

Lengyel E (2010) Ovarian cancer development and metastasis. Am J Pathol 177(3): 1053-1064.

Leroy C, Shen Q, Strande V, Meyer R, McLaughlin ME, Lezan E, Bentires-Alj M, Voshol H, Bonenfant D, Alex Gaither L (2015) CUB-domaincontaining protein 1 overexpression in solid cancers promotes cancer cell growth by activating Src family kinases. Oncogene 34(44): 5593-5598.

Liu H, Ong SE, Badu-Nkansah K, Schindler J, White FM, Hynes RO (2011) CUB-domain-containing protein 1 (CDCP1) activates Src to promote melanoma metastasis. Proc Natl Acad Sci USA 108(4): 1379-1384.

McCluggage WG (2011) Morphological subtypes of ovarian carcinoma: a review with emphasis on new developments and pathogenesis. Pathology 43(5): 420-432.

Mittal K, Soslow R, McCluggage WG (2008) Application of immunohistochemistry to gynecologic pathology. Arch Pathol Lab Med 132(3): 402-423.
Miyazawa Y, Uekita T, Hiraoka N, Fujii S, Kosuge T, Kanai Y, Nojima Y, Sakai R (2010) CUB domain-containing protein 1, a prognostic factor for human pancreatic cancers, promotes cell migration and extracellular matrix degradation. Cancer Res 70(12): 5136-5146.

Obermair A, Hagenauer S, Tamandl D, Clayton RD, Nicklin JL, Perrin LC, Ward BG, Crandon AJ (2001) Safety and efficacy of low anterior en bloc resection as part of cytoreductive surgery for patients with ovarian cancer. Gynecol Oncol 83(1): 115-120.

Perets R, Wyant GA, Muto KW, Bijron JG, Poole BB, Chin KT, Chen JY, Ohman AW, Stepule CD, Kwak S, Karst AM, Hirsch MS, Setlur SR, Crum CP, Dinulescu DM, Drapkin R (2013) Transformation of the fallopian tube secretory epithelium leads to high-grade serous ovarian cancer in Brca;Tp53;Pten models. Cancer Cell 24(6): 751-765.

Provencher DM, Lounis H, Champoux L, Tetrault M, Manderson EN, Wang JC, Eydoux P, Savoie R, Tonin PN, Mes-Masson AM (2000) Characterization of four novel epithelial ovarian cancer cell lines. In Vitro Cell Dev Biol Anim 36(6): 357-361.

Razorenova OV, Finger EC, Colavitti R, Chernikova SB, Boiko AD, Chan CK, Krieg A, Bedogni B, LaGory E, Weissman IL, Broome-Powell M, Giaccia AJ (2011) VHL loss in renal cell carcinoma leads to up-regulation of CUB domain-containing protein 1 to stimulate PKC\{delta\}-driven migration. Proc Natl Acad Sci USA 108(5): 1931-1936.

Scott CL, Mackay HJ, Haluska P Jr (2014) Patient-derived xenograft models in gynecologic malignancies. Am Soc Clin Oncol Educ Book e258-e266.

Sherman-Baust CA, Kuhn E, Valle BL, Shih IeM, Kurman RJ, Wang TL, Amano T, Ko MS, Miyoshi I, Araki Y, Lehrmann E, Zhang Y, Becker KG, Morin PJ (2014) A genetically engineered ovarian cancer mouse model based on fallopian tube transformation mimics human high-grade serous carcinoma development. J Pathol 233(3): 228-237.

Siegel R, Naishadham D, Jemal A (2013) Cancer statistics, 2013. CA Cancer J Clin 63(1): 11-30.

Singh N, Gilks CB, Wilkinson N, McCluggage WG (2015) Assessment of a new system for primary site assignment in high-grade serous carcinoma of the fallopian tube, ovary, and peritoneum. Histopathology 67(3): 331-337.

Siva AC, Wild MA, Kirkland RE, Nolan MJ, Lin B, Maruyama T, Yantiri-Wernimont F, Frederickson S, Bowdish KS, Xin H (2008) Targeting CUB domain-containing protein 1 with a monoclonal antibody inhibits metastasis in a prostate cancer model. Cancer Res 68(10): 3759-3766.

Uekita T, Tanaka M, Takigahira M, Miyazawa Y, Nakanishi Y, Kanai Y, Yanagihara K, Sakai R (2008) CUB-domain-containing protein 1 regulates peritoneal dissemination of gastric scirrhous carcinoma. Am J Pathol 172(6): 1729-1739.

Vaughan S, Coward JI, Bast Jr RC, Berchuck A, Berek JS, Brenton JD, Coukos G, Crum CC, Drapkin R, Etemadmoghadam D, Friedlander M, Gabra H, Kaye SB, Lord CJ, Lengyel E, Levine DA, McNeish IA, Menon U, Mills GB, Nephew KP, Oza AM, Sood AK, Stronach EA, Walczak H, Bowtell DD, Balkwill FR (2011) Rethinking ovarian cancer: recommendations for improving outcomes. Nat Rev Cancer 11(10): 719-725.

Wortmann A, He Y, Christensen ME, Linn M, Lumley JW, Pollock PM, Waterhouse NJ, Hooper JD (2011) Cellular settings mediating Src Substrate switching between focal adhesion kinase tyrosine 861 and CUB-domain-containing protein 1 (CDCP1) tyrosine 734. J Biol Chem 286(49): 42303-42315.

Wortmann A, He Y, Deryugina EI, Quigley JP, Hooper JD (2009) The cell surface glycoprotein CDCP1 in cancer-insights, opportunities, and challenges. IUBMB Life 61(7): 723-730.

Yemelyanova A, Vang R, Kshirsagar M, Lu D, Marks MA, Shih IeM, Kurman RJ (2011) Immunohistochemical staining patterns of p53 can serve as a surrogate marker for TP53 mutations in ovarian carcinoma: an immunohistochemical and nucleotide sequencing analysis. Mod Pathol 24(9): 1248-1253.

This work is published under the standard license to publish agreement. After 12 months the work will become freely available and the license terms will switch to a Creative Commons AttributionNonCommercial-Share Alike 4.0 Unported License.

Supplementary Information accompanies this paper on British Journal of Cancer website (http://www.nature.com/bjc) 